\title{
Pathways from Child Sexual and Physical Abuse to Sexual and Physical Intimate Partner Violence Victimization through Attitudes toward Intimate Partner Violence
}

\author{
Isabell Schuster ${ }^{1}\left[\right.$ D Paulina Tomaszewska ${ }^{2}$ \\ Published online: 1 August 2020 \\ (C) The Author(s) 2020
}

\begin{abstract}
Although many studies have shown that victims of child abuse have an increased vulnerability to revictimization in intimate relationships, the underlying mechanisms are not yet sufficiently well understood. Therefore, this study aimed at examining this relationship for both sexual and physical forms of violence as well as investigating the potential mediating role of attitudes toward sexual and physical intimate partner violence (IPV). Also, the potential moderating role of gender was explored. Sexual and physical child abuse and IPV victimization in adulthood as well as attitudes toward the respective form of IPV were assessed among 716 participants (448 female) in an online survey. The path analyses showed that child sexual abuse was positively linked to sexual IPV victimization among both women and men, whereas child physical abuse was positively associated with physical IPV victimization among women only. Furthermore, the relationship between both forms of child abuse and IPV victimization was mediated through more supportive attitudes toward the respective forms of IPV, but only among men. This study provides novel insights regarding the links between sexual and physical child abuse and revictimization in adulthood, suggesting that supporting attitudes toward IPV may be seen as vulnerability factor for revictimization. The moderating role of gender is especially discussed.
\end{abstract}

Keywords Child abuse $\cdot$ Intimate partner violence $\cdot$ Attitudes toward intimate partner violence $\cdot$ Gender

Sexual and physical abuse in childhood is a major public health issue worldwide with serious consequences for the victims. Meta-analytic evidence has shown that problems include a heightened risk of suicide attempts and suicide ideation (Angelakis et al. 2019), depression and anxiety (Lindert et al. 2014), and substance abuse (Chwartzmann Halpern et al. 2018), to name only a few adverse outcomes. In addition

Isabell Schuster and Paulina Tomaszewska shared first authorship

During the analysis and first manuscript writing phase, Isabell Schuster was affiliated with the University of Potsdam, Germany. During the revision phase, she was affiliated with the Free University of Berlin, Germany.

Isabell Schuster

isabell.schuster@fu-berlin.de

1 Department of Education and Psychology, Free University of Berlin, Berlin, Germany

2 Department of Psychology, University of Potsdam, Potsdam, Germany to that, victims of sexual or physical abuse in childhood do not only experience a wide range of negative outcomes through their initial victimization, but they also have a higher vulnerability to revictimization in adulthood (for meta-analyses, see Neumann et al. 1996; Roodman and Clum 2001), creating a circle of victimization. One important key to understanding the relationship between abuse in childhood and revictimization in adulthood is in particular to look at beliefs that justify violence as a normal element of relationships (e.g., Morris et al. 2015). Although past research has started to examine these links, most studies included all-female samples and did not differentiate between different forms of victimization. Therefore, the purpose of the present study was to examine the mediating role of attitudes toward sexual and physical intimate partner violence (IPV) between sexual and physical abuse in childhood and revictimization in intimate adult relationships, studying both women and men. Investigating the potential mediators between child sexual and physical abuse and revictimization is especially important for the development of evidence-based prevention programs against physical and sexual aggression. In the present paper, the term 
revictimization refers to the repeated experience of sexual and/ or physical violence in adulthood followed by sexual and/or physical abuse in childhood.

\section{Sexual and Physical Abuse in Childhood}

The World Health Organization (WHO 2006) defines child sexual abuse (CSA) as the 'involvement of a child in sexual activity that he or she does not fully comprehend, is unable to give informed consent to, or for which the child is not developmentally prepared, or else that violates the laws or social taboos of society' (p. 10). The meta-analysis of self-report studies by Stoltenborgh et al. (2011) found a prevalence of $18.0 \%$ among female and $7.6 \%$ among male participants, demonstrating not only its widespread scale, but also a substantial gender difference, with higher rates of CSA among females than among males. In Germany, recent representative studies found similar rates to those presented above, ranging between $8.4 \%$ and $18.0 \%$ among females and between $2.3 \%$ and 9.3\% among males (Hellmann 2014; Iffland et al. 2013; Witt et al. 2017). An even higher rate of $49 \%$ among women has been found in a non-representative sample (Langer and Catani 2016).

Child physical abuse (CPA) is defined by the WHO (2006) as the 'intentional use of physical force against a child that results in - or has a high likelihood of resulting in - harm for the child's health, survival, development or dignity' (p. 10) and can include, for example, hitting, beating, and burning. Based on meta-analytic evidence from self-report studies worldwide, it is estimated that almost one quarter of adults (22.6\%) have experienced physical abuse in childhood, with similar rates for women and men (Stoltenborgh et al. 2013), showing that a substantial proportion of the population around the globe is affected. Representative data from the German population yielded prevalence rates around 12\% (Iffland et al. 2013; Witt et al. 2017), with no gender differences. By contrast, a much higher prevalence rate of $36 \%$ was found in the allfemale community sample by Langer and Catani (2016), albeit not being representative for Germany.

\section{Revictimization in Adulthood}

A major concern is that CSA and CPA do not only have numerous adverse effects on physical and mental health, but also increase the odds of revictimization experiences in adulthood. A large body of studies has conclusively demonstrated that CSA increases the vulnerability to sexual revictimization in adulthood, especially in intimate partner relationships (e.g., Arata 2002; Classen et al. 2005; Ullman and Najdowski 2011). Classen et al. (2005) conclude that about two of three persons who were sexually abused in childhood are sexually revictimized in adulthood. Although much less research attention has been paid to physical revictimization in adulthood (Coid et al. 2001), there is also evidence that CPA is associated with a higher vulnerability to adult physical victimization (Dietrich 2007; Langer and Catani 2016; Richards et al. 2017).

Furthermore, numerous studies have shown that sexual and physical forms of child and adult victimization do often cooccur within the same time period (e.g., Kim et al. 2017; Schuster and Krahé 2019; Turner et al. 2017). There is also evidence that sexual and physical forms of child and adult victimization are often cross-associated (Langer and Catani 2016; Ports et al. 2016). For example, Smith et al. (2003) have demonstrated that women who reported any type of child abuse (CSA, CPA, or witnessing parental violence) had a higher vulnerability to sexual and/or physical victimization at college.

\section{The Role of Attitudes toward Intimate Partner Violence (IPV)}

A central question concerns the psychological mechanisms that may make victims of child abuse more vulnerable to adult revictimization, especially in intimate relationships. The link between accepting interpersonal violence and subsequent perpetration of violence, both sexual and/or physical, is well established (e.g., Kinsfogel and Grych 2004; O'Keefe 1997; Reyes et al. 2016; Smith-Darden et al. 2017; Temple et al. 2013; see Vagi et al. 2013, for a review). However, much less is known about the link between accepting perpetrating sexual and/or physical IPV and experiencing sexual and/or physical IPV as well as about the role of accepting these forms of violence as potential mediators between sexual and/or physical child abuse and revictimization.

Based on the social learning theory (Bandura 1977), individuals who have experienced or witnessed family violence may learn to be a perpetrator, but also to be a victim. Because parents serve to children as valuable role models, children may learn that violent acts are appropriate and that, in turn, may form their attitudes and behaviors. According to that, individuals who have learned that violence against a loved/ close person is acceptable may also accept to a greater extent violence by an intimate partner, increasing the vulnerability to experience violence in their own intimate relationships. Some empirical evidence consistent with this conceptualization has been identified. Building mostly on cross-sectional data, previous studies have shown that the belief that physical and/or sexual violence in a relationship is normative and acceptable may make a person more vulnerable to be victimized by his or her partner (see Capaldi et al. 2012; Vézina and Herbert 2007, for reviews). It has also been suggested that one of the origins 
of supportive attitudes toward IPV is the exposure to family violence through which individuals may adopt violent norms and scripts (e.g., Copp et al. 2019; Schuster et al. 2020). Further, McDonnell et al. (2010) found that both female and male adolescents who held supportive attitudes toward violence and justified it, reported higher odds of dating victimization, based on a combined score of lifetime physical and emotional victimization in dating relationships. Also, Torres et al. (2012) have demonstrated that both accepting adversarial sexual beliefs and physical IPV were linked to physical victimization among men. Among women, accepting sexual IPV increased the odds of being a victim of physical victimization. And finally, Karlsson et al. (2016) found that accepting dating violence, in addition to witnessing violence between parents, significantly predicted teen dating violence victimization and partially mediated the relationship between witnessing violence between parents and teen dating violence victimization.

Using longitudinal data from 461 youth, Morris et al. (2015) showed that being exposed to harsh discipline, defined as yelling, spanking, slapping, or hitting with a belt, at the age of 11 predicted more accepting beliefs about perpetrating dating violence and the experience of opposite-sex peer aggression at the age of 13. This in turn predicted the experience of dating violence at the age of 18 , combing both physical and emotional forms of dating violence as one outcome.

All this evidence indicates that violence-supporting attitudes may play a substantial role as potential underlying mechanism between exposure to violence in childhood and revictimization in adulthood. Therefore, this study aimed to investigate the mediating role of attitudes toward dating violence in the link between child abuse and violence revictimization, focusing on the physical and sexual forms of child abuse and adulthood revictimization in intimate relationships and the respective forms of attitudes toward IPV.

\section{The Current Study}

Given that most studies focused on CSA und sexual revictimization and evidence on CPA and physical revictimization in adulthood is strongly limited, the purpose of the present study was to examine both forms of violence in childhood and adulthood, addressing this gap in the current literature. Building on that, the respective forms of attitudes toward IPV were investigated as mediators in the link between child abuse and revictimization experiences. Since our main focus lays on sexual and physical forms of abuse and revictimization, we did not assess other forms of violence, such as emotional and psychological victimization, although being part of definitions of violence in childhood and intimate relationships (cf., Capaldi et al. 2012; Vagi et al. 2013; WHO 2006). Although past studies on sexual revictimization focused primarily on women, there is evidence that men may also experience sexual (re-)victimization (see, for example, Desai et al. 2002; Schuster et al. 2016; Stemple et al. 2017; Tomaszewska and Krahé 2018, for empirical evidence). Therefore, we followed a gender-inclusive egalitarian approach (see Turchik et al. 2016, for an outline), examining systematically both women and men as potential victims of both forms of violence.

Based on the existing evidence, we proposed a path model which is shown in Fig. 1. We predicted that CSA would be positively associated with sexual IPV victimization and CPA would be positively associated with physical IPV victimization. Further, we expected that CSA would be positively associated with attitudes toward sexual IPV, which in turn would increase the vulnerability of sexual IPV victimization. We also expected that CPA would be positively associated with attitudes toward physical IPV, which in turn would increase the vulnerability of physical IPV victimization. Because both types of child abuse are intercorrelated, we also expected positive associations between both sexual and physical child and adult victimization experiences as well as between the related attitudes. Finally, we expected that CSA would indirectly predict physical IPV victimization via attitudes toward sexual/physical IPV and CPA would indirectly predict sexual IPV victimization via attitudes toward sexual/ physical IPV. Because gender as a potential moderator in the postulated relationships has not been studied sufficiently, in the present study, we examined whether the proposed pathways are similar or different for women and men.

\section{Method}

\section{Participants}

The initial sample consisted of 720 participants (448 women, 269 men, 3 other gender). One participant below the age of 18 , the age of majority in Germany, was excluded from the sample. Participants who self-identified as other gender $(n=3)$ were also excluded because the sample size was too small for separate analyses. This resulted in a final sample of 716 participants (448 women, 268 men). Mean age of the sample was 25.9 years ( $S D=6.72$, range: $18-64$ years). Men and women did not differ in age. Regarding sexual orientation, most participants (86.1\%) reported being heterosexual. The remaining participants described themselves as bisexual (8.3\%), homosexual (4.5\%), or having another sexual orientation (1.1\%). More men (90.3\%) than women $(83.6 \%)$ self-identified as heterosexual, whereas more women $(11.7 \%)$ than men $(2.6 \%)$ reported being bisexual, $p \mathrm{~s}<.0125$ (corrected alpha level due to multiple comparisons: $.05 / 4)$. No gender differences were found for participants who self-identified as homosexual or having another sexual orientation. The majority of the participants were students of higher 
education $(76.1 \%)$. The remaining participants were working $(20.5 \%)$, unemployed $(1.7 \%)$, unable to work $(0.6 \%)$, housewives/househusbands $(0.3 \%)$, retired $(0.1 \%)$, or had another occupation $(0.7 \%)$.

\section{Measures}

Sexual and Physical Abuse in Childhood To assess both sexual and physical abuse before the age of 14 , we used the respective five-item subscales of the short form of the Childhood Trauma Questionnaire (CTQ-SF; Bernstein et al. 2003; German version by Wingenfeld et al. 2010). The scale on sexual abuse includes, for example, the item 'Someone tried to make me do sexual things or watch sexual things', and an example item of physical abuse is 'People in my family hit me so hard that it left me with bruises or marks'. Responses were made on a five-point scale ranging from 1 (never) to 5 (very often). For descriptive statistics and hypothesis testing, sum scores were computed based on high internal consistency ( $\alpha=.94$ for sexual abuse; $\alpha=.81$ for physical abuse). To examine prevalence rates, a severity score has been created based on the CTQ manual's cut-off scores (Bernstein and Fink 1998; Witt et al. 2017). For sexual abuse: none (5), low to moderate (6-7), moderate to severe (8-12), and severe to extreme (13-25). For physical abuse: none to low (5-7), low to moderate (8-9), moderate to severe (10-12), and severe to extreme (13-25).

\section{Attitudes toward Sexual and Physical Intimate Partner} Violence The extent to which participants found using sexual and physical violence toward an intimate partner acceptable was measured by gender-appropriate scales of the Attitudes toward Dating Violence Scales by Price and Byers (1999). This means that participants were asked about the acceptance of sexual and physical violence toward an intimate partner by a person of their gender. Hence, male participants completed the respective 12 items of the Attitudes toward Male Physical/Sexual Dating Violence Scale and female participants received the respective 12 items of the Attitudes toward Female Physical/ Sexual Dating Violence Scale. To assess attitudes toward male physical IPV, an example item for men was 'It is never O.K. for a man to hit his partner'. To measure attitudes toward female sexual IPV, an example item for women was 'It is alright for a woman to force her partner to kiss her'. Although the original scales refer to dating violence, our participants were asked to think about their intimate partners in general and not specifically about their dating partners. In addition, we used wording that can refer to partners of all gender groups (male, female, other), which allowed to think about the person with whom the participants were in a relationship. Response options to the items ranged from 1 (strongly disagree) to 5 (strongly agree). For attitudes toward physical IPV, Cronbach's alpha was .82 for the male and .77 for the female version. For attitudes toward sexual IPV, Cronbach's alpha was .78 for the male and .71 for the female version. Mean scores were computed for attitudes toward physical IPV and attitudes toward sexual IPV.

Sexual and Physical Intimate Partner Violence Victimization To measure experiences of both sexual and physical IPV since the age of 14, the age of consent in Germany, the seven-item sexual coercion and 12-item physical assault subscales of the revised Conflict Tactics Scales (CTS2; Straus et al. 1996) were used. As in the measurement of attitudes, wording that refers to all gender options was applied. Sample items include 'My partner physically forced sex' for the sexual coercion subscale, and 'My partner beat me up' for the physical assault subscale. Responses were made on a five-point scale ranging from 1 (never) to 5 (very often). To assess prevalence rates, dichotomous scores of sexual and physical IPV victimization were computed by assigning all participants who reported no victimization (response of 'never' to all items) to the non-victim category (coded as 0 ). If participants responded $>1$ at least once, they were classified as victims (coded as 1). This scoring procedure corresponds with Straus et al. (1996) and is consistent with previous studies (e.g., Krahé and Berger 2005; Smith et al. 2003). To test descriptive statistics and our hypotheses, mean scores for sexual and physical IPV victimization, respectively, were computed given high internal consistency ( $\alpha=.85$ for sexual IPV victimization and $\alpha=.90$ for physical IPV victimization).

\section{Procedure}

Approval of the study design and all instruments was obtained from the Ethics Committee of the authors' university. Data were collected in an online survey entitled 'Experience of violence in childhood and adulthood' in the summer term 2019. The study was conducted in German. To recruit participants, the study was advertised in social media groups, such as student groups of several study fields (e.g., mathematics, politics, etc.) at universities and institutions of higher education in Germany. Detailed information about the study was provided on the first page of the survey, and active consent was required before being able to proceed to the questionnaire. Because thinking about past sexual and physical victimization may recall negative memories, we provided a link to a list with contact details of counseling agencies on each survey page containing questions about victimization. In return for participation, five gift cards were raffled among all participants. With respect to translation, German versions of the instruments were created by a careful translation of the English originals into German and a back-translation from German into English by fluent speakers of the two languages.

\section{Analytic Plan}

To examine prevalence rates of sexual and physical victimization in childhood, we created cut-off scores based on Bernstein and Fink (1998), as described in the Measures 
section. For sexual/physical IPV victimization, dichotomous scores were computed (also see Measures). To test gender differences in prevalence rates, we used $\mathrm{Chi}^{2}$ analyses. Additionally, we present descriptive statistics for both forms of child- and adulthood victimization, treating them as continuous variables. Gender differences in child sexual/physical abuse, attitudes toward sexual/physical IPV, and sexual/ physical IPV victimization were tested by employing a multivariate analysis of variance (MANOVA).

The path model was examined with Mplus (version 8.2, Muthén and Muthén 2017) and all variables were treated as continuous. We used the robust maximum likelihood (MLR) estimator, taken the non-normal distribution of the data into account. Missing data was handled by the Full Information Maximum Likelihood (FIML) approach (Enders 2010). The significance of all direct and indirect pathways (mediations) was assessed by $95 \%$ and $99 \%$ bias-corrected bootstrapped confidence intervals based on 10,000 replications. As the bootstrap procedure is not possible with the MLR estimator, we used the maximum likelihood (ML) estimator for these analyses. CSA and CPA as well as sexual and physical IPV victimization were controlled for age because age was positively correlated with CPA among both gender groups $\left(r_{\text {women }}=.13, p=.007 ; r_{\text {men }}=.13, p=.033\right)$. Although CSA as well as sexual and physical IPV victimization were not significantly correlated with age, a significant association might be found in the path model when relations between all variables are considered. Although some of the correlations for women were not significant at the bivariate level (see Table 2), we computed the final model specifying all paths for both gender groups because intercorrelations may potentially change the bivariate associations between variables.

To test whether gender plays a moderating role in the path model, we applied a two-step procedure. In the first step, a multi-group model by gender was tested in which all paths for women and men were constrained to be equal (constrained model). In the second step, a multi-group model by gender was estimated in which all paths for women and men were unconstrained, i.e., being allowed to vary between both groups (unconstrained model). To test the moderating role of gender, we compared the constrained and unconstrained model, using the Satorra-Bentler scaled $\mathrm{Chi}^{2}$ difference test.

\section{Results}

\section{Prevalence of Sexual and Physical Victimization in Childhood and Adulthood}

Prevalence rates of sexual and physical abuse in childhood for women and men, based on cut-off scores, are presented in Table 1. For CSA, a significant gender difference was found, $\chi^{2}(3, N=715)=45.03, p<.001$. Post-hoc analyses demonstrated significant gender differences for each category of severity, with more men than women reporting no victimization and more women than men reporting severe forms of CSA. For CPA, no gender difference was found, $\chi^{2}(3, N=$ $716)=0.84, p=.840$. Similarly, more women $(37.9 \%)$ reported sexual IPV victimization than did men $(27.4 \%), \chi^{2}(1, N=$ $704)=8.09, p=.004$. No difference was found for physical IPV victimization between women (52.5\%) and men (56.3\%), $\chi^{2}(1, N=705)=0.95, p=.330$.

\section{Descriptive Statistics and Correlations}

A MANOVA was employed to test gender differences in child sexual/physical abuse, attitudes toward sexual/physical IPV, and sexual/physical IPV victimization. As shown in Table 2, women reported CSA and sexual IPV victimization more often than did men. More justifying attitudes toward sexual IPV were found among men than women but they reported on a different type of attitudes (male- vs. female-perpetrated violence). No further gender differences emerged. Regarding correlations, all variables were significantly positively correlated among men. Among women, attitudes toward sexual/physical IPV were not significantly correlated with child sexual/ physical abuse as well as sexual/physical IPV victimization. All remaining variables were significantly positively correlated.

\section{Prediction of Sexual and Physical IPV Victimization}

First, we tested whether gender plays a moderating role. The constrained model showed only an acceptable fit, $\chi^{2}(23, N=$ $715)=67.79, p<.001, \mathrm{CFI}=0.90, \mathrm{RMSEA}=0.0790 \% \mathrm{CI}$ $[.05, .09]$, SRMR $=.13$. The unconstrained model had a good fit with the data, $\chi^{2}(4, N=715)=2.72, p=.606, \mathrm{CFI}=1.00$, RMSEA $=0.0090 \%$ CI $[.00, .07]$, SRMR $=.01$. The comparison of the two models revealed that the fit of the unconstrained model was significantly better, Satorra-Bentler scaled $\mathrm{Chi}^{2}$ difference test $\chi^{2}(19)=62.14, p<.001$. Hence, the unconstrained model was used as the final model. Gender differences in the direct and mediating pathways were tested in a post-hoc analysis, using the Mplus' model constraint option. The final model is shown in Fig. 1.

As predicted, CSA was positively associated with sexual IPV victimization among both women and men (see Fig. 1). This relationship was mediated through more accepting attitudes toward sexual IPV among men $(\beta=.04,95 \%$ $\mathrm{CI}=[.006, .124])$, but not among women $(\beta=-.01,95 \%$ $\mathrm{CI}=[-.021, .001])$, partly confirming our prediction . Furthermore, the mediating pathways for women and men differed significantly $(95 \% \mathrm{CI}=[-.033,-.002])$.

Also, as expected, CPA was positively associated with physical IPV victimization among women, but not among men (see Fig. 1). A mediation effect from child physical abuse 
Table 1 Prevalence of sexual and physical abuse in childhood in percent

\begin{tabular}{|c|c|c|c|c|}
\hline & None-low & Low-moderate & Moderate-severe & Severe-extreme \\
\hline \multicolumn{5}{|c|}{ Child sexual abuse } \\
\hline Women & $58.0 *$ & $17.6^{*}$ & $13.6^{*}$ & $10.7 *$ \\
\hline Men & $82.0 *$ & $9.4^{*}$ & $5.6^{*}$ & $3.0 *$ \\
\hline \multicolumn{5}{|c|}{ Child physical abuse } \\
\hline Women & 79.5 & 7.8 & 8.3 & 4.5 \\
\hline Men & 81.3 & 8.2 & 6.7 & 3.7 \\
\hline
\end{tabular}

Gender difference tested with $\chi^{2}: * p<.006$ (corrected for multiple testing: .05/8)

to physical IPV victimization via more justifying attitudes toward physical IPV victimization was found among men $(\beta=.06,99 \% \mathrm{CI}=[.002, .196])$, but not among women $(\beta=-.00,95 \% \mathrm{CI}=[-.015, .008])$. Mediating pathways between women and men differed again significantly $(95 \%$ $\mathrm{CI}=[-.029,-.002])$.
Beyond the links within the same type of victimization, CSA was positively associated with physical IPV victimization among women but not among men (see Fig. 1). Among men, this association was mediated through more justifying attitudes toward sexual IPV $(\beta=.03,95 \% \mathrm{CI}=[.001, .118])$ as well as physical IPV $(\beta=.05,95 \% \mathrm{CI}=[.009, .150])$. The

Table 2 Means, standard deviations, and bivariate correlations

\begin{tabular}{|c|c|c|c|c|c|c|c|c|c|c|}
\hline Construct & $\begin{array}{l}\text { Number } \\
\text { of items }\end{array}$ & $\begin{array}{l}M_{\text {total }} \\
(S D)\end{array}$ & $\begin{array}{l}M_{f} \\
(S D)\end{array}$ & $\begin{array}{l}M_{m} \\
(S D)\end{array}$ & (1) & $(2)$ & (3) & (4) & $(5)$ & $(6)$ \\
\hline (1) Child sexual abuse & 5 & $\begin{array}{l}6.55 \\
(3.36)\end{array}$ & $\begin{array}{l}7.08 * * * \\
(3.83)\end{array}$ & $\begin{array}{l}5.66 * * * \\
(2.08)\end{array}$ & - & $.39 * * *$ & -.07 & -.07 & $.36^{* * *}$ & $.32 * * *$ \\
\hline (2) Child physical abuse & 5 & $\begin{array}{l}6.51 \\
(2.76)\end{array}$ & $\begin{array}{l}6.55 \\
(2.79)\end{array}$ & $\begin{array}{l}6.43 \\
(2.71)\end{array}$ & $33 . * * *$ & - & -.03 & -.04 & $.17 * * *$ & $.25 * * *$ \\
\hline (3) Attitudes toward sexual IPV & 12 & $\begin{array}{l}1.44 \\
(0.48)\end{array}$ & $\begin{array}{l}1.39 * * * \\
(0.41)\end{array}$ & $\begin{array}{l}1.53 * * * \\
(0.57)\end{array}$ & $.23 * * *$ & $.21 * *$ & - & $.31 * * *$ & .06 & .05 \\
\hline (4) Attitudes toward physical IPV & 12 & $\begin{array}{l}1.51 \\
(0.52)\end{array}$ & $\begin{array}{l}1.50 \\
(0.49)\end{array}$ & $\begin{array}{l}1.52 \\
(0.58)\end{array}$ & $.26 * * *$ & $.26 * * *$ & $.60 * * *$ & - & .06 & .07 \\
\hline (5) Sexual IPV victimization & 7 & $\begin{array}{l}1.26 \\
(0.53)\end{array}$ & $\begin{array}{l}1.29^{*} \\
(0.55)\end{array}$ & $\begin{array}{l}1.20^{*} \\
(0.48)\end{array}$ & $.28 * * *$ & $.26 * * *$ & $.34 * * *$ & $.29 * * *$ & - & $.54 * * *$ \\
\hline (6) Physical IPV victimization & 12 & $\begin{array}{l}1.25 \\
(0.44)\end{array}$ & $\begin{array}{l}1.23 \\
(0.42)\end{array}$ & $\begin{array}{l}1.30 \\
(0.48)\end{array}$ & $.29 * * *$ & $.28 * * *$ & $.42 * * *$ & $.47 * * *$ & $.64 * * *$ & - \\
\hline
\end{tabular}

Note. $f=$ female, $m=$ male. Above the diagonal: correlation coefficients for women; below the diagonal: correlation coefficients for men. $P$-values for gender differences and correlation coefficients: $* p<.05, * * p<.01, * * * p<.001$

Fig. 1 Path model with standardized coefficients for women (before slash) and men (after slash). CSA and CPA as well as sexual and physical IPV victimization controlled for age. Only direct effects are presented. The shaded coefficients differ significantly between women and men (95\% CI). Model fit: $\chi^{2}$ (4, $N=715)=2.72, p=.606 ; \mathrm{CFI}=$ $1.00 ;$ RMSEA $=.00,90 \%$ CI $[.00$, $.07] ; \mathrm{SRMR}=.01 . * p<.05(95 \%$ CI), $* * p<.01(99 \% \mathrm{CI})$

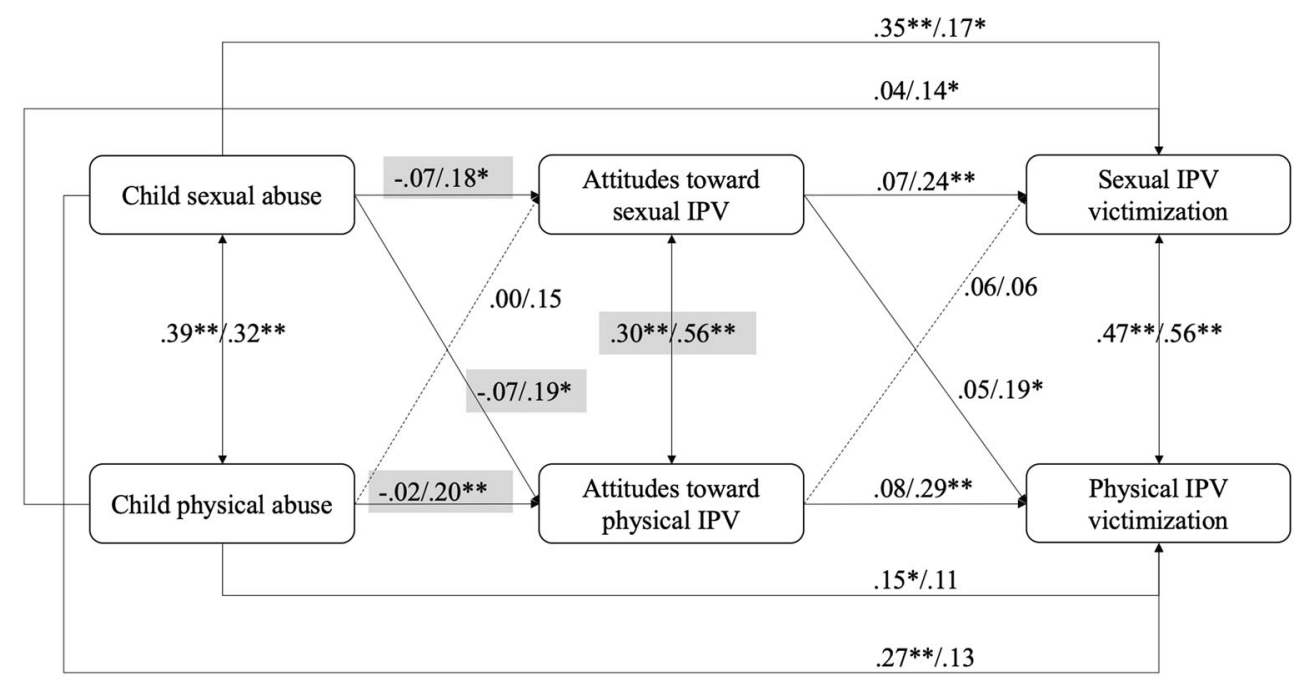


respective pathways were nonsignificant among women and differed significantly from the male ones $(95 \% \mathrm{CI}=[-.031$, $-.001]$ for pathway via attitudes toward sexual IPV; $95 \%$ $\mathrm{CI}=[-.041,-.002]$ for pathway via attitudes toward physical IPV). Furthermore, CPA was positively linked to sexual IPV victimization among men, but not among women. No further mediation effects were found. In terms of the associations between age and both forms of sexual and physical child and adult victimization experiences, only one significant association between age and CPA was found among women $(\beta=.12,95 \% \mathrm{CI}=[.022, .233])$.

\section{Discussion}

The purpose of this study was to examine sexual and physical child abuse and revictimization in intimate relationships in adulthood as well as the mediating role of attitudes toward sexual and physical IPV between child abuse and revictimization experiences among both women and men. In addition, the potential moderating role of gender was explored in the analyses.

In the present study, prevalence rates of child abuse, both sexual and physical, were slightly higher compared to studies using representative samples (e.g., Hébert et al. 2009; Witt et al. 2017). This may be due to advertising our survey as study on experiences of violence in childhood and adulthood. Given the sensitive topic, it is ethically necessary to inform participants about the content, and this may have made individuals with victimization experiences more willing to participate. Despite the substantial rates, the pattern of gender differences is consistent with previous research (Stoltenborgh et al. 2011, 2013), showing that more women than men report CSA, whereas no gender difference was found for CPA.

Regarding sexual IPV victimization, $37.9 \%$ of women and $27.5 \%$ of men reported such an experience. Chan et al. (2008) found a similar rate among women $(39.6 \%)$ but a higher rate for men $(44.3 \%)$ in a German convenience sample using the same instrument (CTS2). In terms of physical IPV victimization, the rates in the current study were substantially higher than in the Chan et al. (2008) study (52.5\% vs. $26 \%$ for women and $56.3 \%$ vs. $36.1 \%$ for men). Perhaps, as in the case of the CSA findings, individuals who were affected by physical IPV were more motivated to participate. However, the pattern of gender differences was generally consistent with previous studies, showing higher prevalence rates in sexual victimization experienced from a current or former partner among women than among men (e.g., Smith et al. 2017). In terms of experiencing physical violence in intimate relationships, studies using CTS2 scales have found no or minor gender differences (Chan et al. 2008; Doroszewicz and Forbes 2008; Torres et al. 2012).
With regard to our predictions, as expected, CSA was positively associated with sexual IPV victimization in both men and women, being consistent with the reviewed literature (e.g., Classen et al. 2005; Ullman and Najdowski 2011). Likewise, CPA was positively associated with physical IPV victimization among women, but not among men, confirming only partially our hypothesis. Given that a large body of evidence is based on all-female samples, in the past, little attention has been paid to potential gender differences. Similar to the results of the present study, Dietrich (2007) found that CPA was significantly associated with physical revictimization among women, but not among men. Beyond these direct relationships, CSA was also positively linked to physical IPV victimization among women but not among men, and CPA was positively associated with sexual IPV victimization among men, but not among women. Taken together, evidence from the current study emphasizes the vulnerability of both forms of child abuse to subsequent detrimental experiences in adulthood.

Looking at the mediating role of attitudes toward IPV, as expected, the relationship between CSA and sexual IPV victimization was mediated through more justifying attitudes toward sexual IPV, but only among men, not among women. Similarly, more justifying attitudes toward physical IPV mediated the relationship between CPA and physical IPV victimization, but also only among men. Furthermore, we found that the relationship between CSA and physical IPV victimization was mediated through more justifying attitudes toward physical and sexual IPV among men, but again, not among women. In sum, these results suggest that there are different pathways for both gender groups, as the mediating role of attitudes toward physical and sexual IPV was found among men only.

As for the postulated mediation, previous research has shown that physical abuse in childhood is associated with justifying attitudes toward dating violence (e.g., Morris et al. 2015) and that attitudes approving IPV are linked to IPV victimization (see Capaldi et al. 2012; Vézina and Herbert 2007, for reviews). However, a comparison of our findings with the existing literatures is not straightforward, mainly due to the high variability in the way how attitudes toward (intimate partner) violence were measured, what forms of violence (in childhood and adulthood) were considered, and how they were treated in the analyses. For example, the longitudinal study by Morris et al. (2015) did not differentiate between attitudes toward sexual and physical dating violence and conceptualized attitudes as reactions to hypothetical dating conflicts. Moreover, victimization was treated in this study as a combined score of emotional and physical victimization, as in the study by McDonell et al. (2010) which used cross-sectional data. Karlsson et al. (2016), using cross-sectional data, assessed the acceptance of male-to-female and female-to-male violence as a mediator, as we did, but they examined the association between 
witnessing interparental violence and dating violence victimization, and did not investigate children's own experiences of violence. Despite this great conceptual and methodological variability, the present study adds to the existing body of evidence and may help to understand the role of attitudes toward interpersonal violence as a mediator between child and adult victimization.

Regarding the moderating role of gender, this may be, at least partly, explained by the way we measured attitudes toward IPV. In the present study, we asked men about attitudes toward physical/sexual male IPV and women about attitudes toward physical/sexual female IPV because the same-gender perspective may elicit more valid responses. Our results suggested that, at least in this sample, childhood victimization experiences, both physical and sexual, are much more strongly associated with attitudes toward IPV in men than in women. This may be due to societal norms, associating predominantly men, not women, with the perpetrator role. In line with this, previous research has demonstrated that physical and/or sexual victimization by a woman is generally perceived as being less serious and consequential in comparison to victimization by a man (Espinoza and Warner 2016; Felson and Feld 2009; Sommer et al. 2016). This in turn may also help to explain why in the current study supportive attitudes toward sexual and physical IPV against a partner by a woman did not mediate the relationship between child abuse and adult revictimization in women, as aggressive behavior by women is not part of the scripts of IPV. Especially, it may be that men who have been sexually and physically abused may have internalized violent norms more strongly than women, matching the societal picture of interpersonal violence, which in turn predicted their own revictimization in adulthood. However, whether endorsing attitudes from the opposite-gender perpetrator would provide different or similar pattern of results warrants further research.

Strengths and Limitations We believe that our study has several strengths. First, we followed a gender-inclusive approach by considering both women and men as potential victims of sexual and physical aggression in intimate relationships (see Turchik et al. 2016, for an outline). Men in particular are often not acknowledged as victims of sexual aggression although there is evidence for that (see, for example, Schuster et al. 2016; Stemple et al. 2017; Tomaszewska and Krahé 2018, for empirical evidence). Following a gender-inclusive approach, particularly in the case of sexual IPV, helps to clarify whether there are different processes for women and men, making them more vulnerable to revictimization. Second, we collected our data online given that participants perceive greater anonymity in the online environment than completing questionnaires of sensitive data in a laboratory room (Brock et al. 2015).

At the same time, our study is not without limitations. First, our results are based on a cross-sectional correlational design, which does not permit to draw causal conclusions. Therefore, longitudinal studies, employing cross-lagged panel designs, are needed, in particular to investigate bidirectional links between attitudes toward sexual/physical IPV and sexual/ physical IPV victimization over time. Second, the present study was advertised as a survey on experience of violence in childhood and adulthood, and a self-selection bias of especially vulnerable participants cannot be ruled out completely. Therefore, the pattern of results found in the current study needs to be examined in a representative sample in the future. Third, in the measurement of sexual and physical abuse in childhood, we did not assess the perpetrator's role and gender (e.g., mother, father). This information would allow an even more specific understanding how experiences of abuse in childhood are associated with attitudes toward IPV and IPV victimization in adulthood. This would also broaden the understanding whether adversarial experiences in the childhood from a same-sex perpetrator may have a different impact on subsequent attitudes and behaviors than such experiences from an opposite-sex perpetrator. Fourth, it is also a limitation that only the same-gender perspective in attitudes toward sexual and physical IPV was considered. This perspective was used in the present study because it may be closer to the participants' behavioral standards (male vs. female behavior) and could help them to better identify with the question and, in turn, elicit more valid responses. Also, because scores regrading accepting violence are generally rather low (e.g., Price and Byers 1999; Tomaszewska and Krahé 2016), the best way to elicit participants' responses on attitudes toward violence may be from the same-gender perspective. Fifth, the Cronbach's alpha was only acceptable for most of the subscales of attitudes toward sexual and physical IPV, being however similar to the scores reported in Price and Byers (1999). Sixth, the number of participants who self-identified as nonheterosexual was too small to test whether there are different mechanisms as a function of sexual orientation. Future research should seek to include lesbian, gay, bisexual, and transgender participants, considering that they are especially vulnerable to sexual and physical IPV victimization (Dank et al. 2014).

\section{Implications for Future Research}

The present study provides several implications for further research. To better understand the psychological mechanisms making victims of child abuse more vulnerable to adult IPV victimization, first, the different types of victimization in child- and adulthood should be measured and analyzed separately. Especially for the measurement, good practice criteria, including for example the use of validated instruments, should be followed (cf., Krahé and Vanwesenbeeck 2016). Second, attitudes toward IPV should also be assessed for the different forms (e.g., physical, sexual), allowing a cross-classification 
of the different types of assaults, especially considering that they often co-occur (Kim et al. 2017; Schuster and Krahé 2019; Turner et al. 2017). Regarding the measurement of attitudes toward IPV, future studies may include both same- and opposite-gender perpetrator perspectives to examine the potential moderating role of gender in the mediating processes between child and adult victimization. Although not within the scope of the present study, future research should not only include sexual and physical victimization in child- and adulthood and the respective attitudes toward IPV, but also assess other types of victimization (e.g., emotional victimization). Third, going also beyond our study design, longitudinal data should be used to examine the discussed pathways. Following these suggestions may contribute to a more holistic comprehension how different types of abuse in childhood may form accepting attitudes toward IPV and increase an individual's vulnerability to victimization in adult intimate relationships.

Altogether, the present study provides novel insights regarding the links between child abuse and revictimization in adulthood, suggesting that supporting attitudes toward IPV may be seen as vulnerability factor for revictimization. Furthermore, this study also indicates that there are different pathways from sexual and physical child abuse to sexual and physical IPV victimization for both gender groups. This in turn may be crucial for informing intervention programs targeting attitudes toward IPV as potential factor that might be changed in such programs.

Acknowledgments The authors are grateful to Jill Kraus and Dorle Proske for their support.

Funding Information Open access funding provided by Projekt DEAL.

Open Access This article is licensed under a Creative Commons Attribution 4.0 International License, which permits use, sharing, adaptation, distribution and reproduction in any medium or format, as long as you give appropriate credit to the original author(s) and the source, provide a link to the Creative Commons licence, and indicate if changes were made. The images or other third party material in this article are included in the article's Creative Commons licence, unless indicated otherwise in a credit line to the material. If material is not included in the article's Creative Commons licence and your intended use is not permitted by statutory regulation or exceeds the permitted use, you will need to obtain permission directly from the copyright holder. To view a copy of this licence, visit http://creativecommons.org/licenses/by/4.0/.

\section{References}

Angelakis, I., Gillespie, E. L., \& Panagioti, M. (2019). Childhood maltreatment and adult suicidality: A comprehensive systematic review with meta-analysis. Psychological Medicine, 49, 1057-1078. https://doi.org/10.1017/S0033291718003823.

Arata, C. M. (2002). Child sexual abuse and sexual victimzation. Clinical Psychology: Science and Practice, 9, 135-164. https://doi.org/10. 1093/clipsy/9.2.135.
Bandura, A. (1977). Social learning theory. New York: General Learning Press.

Bernstein, D., \& Fink, L. (1998). Childhood trauma questionnaire: A retrospective self-report. San Antonio: The Psychological Corporation.

Bernstein, D. P., Stein, J. A., Newcomb, M. D., Walker, E., Pogge, D., Ahluvalia, T., Stokes, J., Handelsman, L., Medrano, M., Desmond, D., \& Zule, W. (2003). Development and validation of a brief screening version of the childhood trauma questionnaire. Child Abuse and Neglect, 27, 169-190. https://doi.org/10.1016/S01452134(02)00541-0.

Brock, R. L., Barry, R. A., Lawrence, E., Rolffs, J., Cerretani, J., \& Zarling, A. (2015). Online administration of questionnaires assessing psychological, physical, and sexual aggression: Establishing psychometric equivalence. Psychology of Violence, 5, 294-304. https://doi.org/10.1037/a0037835.

Capaldi, D. M., Knoble, N. B., Shortt, J. W., \& Kim, H. K. (2012). A systematic review of risk factors for intimate partner violence. Partner Abuse, 3, 231-280. https://doi.org/10.1891/1946-6560.3.2. e4.

Chan, K. L., Straus, M. A., Brownridge, D. A., Tiwari, A., \& Leung, W. C. (2008). Prevalence of dating partner violence and suicidal ideation among male and female university students worldwide. Journal of Midwifery \& Women's Health, 53, 529-537. https://doi.org/10. 1016/j.jmwh.2008.04.016.

Chwartzmann Halpern, S., Barreto Schuch, F., Nichterwitz Scherer, J., Orgler Sordi, A., Pachado, M., Dalbosco, C., et al. (2018). Child maltreatment and illicit substance abuse: A systematic review and meta-analysis of longitudinal studies. Child Abuse Review, 27, 344 360. https://doi.org/10.1002/car.2534.

Classen, C. C., Gronskaya-Palesh, O., \& Aggarwal, R. (2005). Sexual revictimization: A review of the empirical literature. Trauma, Violence, \& Abuse, 6, 103-129. https://doi.org/10.1177/ 1524838005275087.

Coid, J., Petruckevitch, A., Feder, G., Chung, W. S., Richardson, J., \& Moorey, S. (2001). Relation between childhood sexual and physical abuse and risk of revictimisation in women: A cross-sectional survey. Lancet, 358, 450-454. https://doi.org/10.1016/S0140-6736(01) 05622-7.

Copp, J. E., Giordano, P. C., Longmore, M. A., \& Manning, W. D. (2019). The development of attitudes toward intimate partner violence: An examination of key correlates among a sample of young adults. Journal of Interpersonal Violence, 34, 1357-1387. https:// doi.org/10.1177/0886260516651311.

Dank, M., Lachman, P., Zweig, J. M., \& Yahner, J. (2014). Dating violence experiences of lesbian, gay, bisexual, and transgender youth. Journal of Youth and Adolescence, 43, 846-857. https://doi.org/10. 1007/s10964-013-9975-8.

Desai, S., Arias, I., Thompson, M. P., \& Basile, K. C. (2002). Childhood victimization and subsequent adult revictimization assessed in a nationally representative sample of women and men. Violence and Victims, 17, 639-653. https://doi.org/10.1891/vivi.17.6.639.33725.

Dietrich, A. (2007). Childhood maltreatment and revictimization: The role of affect dysregulation, interpersonal relatedness difficulties and posttraumatic stress disorder. Journal of Trauma and Dissociation, 8, 25-51. https://doi.org/10.1300/J229v08n04_03.

Doroszewicz, K., \& Forbes, G. B. (2008). Experiences with dating aggression and sexual coercion among polish college students. Journal of Interpersonal Violence, 23, 58-73. https://doi.org/10.1177/ 0886260507307651.

Enders, C. K. (2010). Applied missing data analysis. New York: Guilford Press.

Espinoza, R., \& Warner, D. (2016). Where do we go from here? Examining intimate partner violence by bringing male victims, female perpetrators, and psychological sciences into the fold. Journal 
of Family Violence, 31, 959-966. https://doi.org/10.1007/s10896016-9881-4.

Felson, R. B., \& Feld, S. L. (2009). When a man hits a woman: Moral evaluations and reporting violence to the police. Aggressive Behavior, 35, 477-488. https://doi.org/10.1002/ab.20323.

Hébert, M., Tourigny, M., Cyr, M., McDuff, P., \& Joly, J. (2009). Prevalence of childhood sexual abuse and timing of disclosure in a representative sample of adults from Quebec. Canadian Journal of Psychiatry, 54, 631-636. https://doi.org/10.1177/ 070674370905400908.

Hellmann, D. F. (2014). Repräsentativbefragung zu Viktimisierungserfahrungen in Deutschland [Representative survey on victimization experiences in Germany]. Retrieved from https:// kfn.de/wp-content/uploads/Forschungsberichte/FB_122.pdf

Iffland, B., Brähler, E., Neuner, F., Häuser, W., \& Glaesmer, H. (2013). Frequency of child maltreatment in a representative sample of the German population. BMC Public Health, 13, 980. https://doi.org/10. 1186/1471-2458-13-980.

Karlsson, M. E., Temple, J. R., Weston, R., \& Le, V. D. (2016). Witnessing interparental violence and acceptance of dating violence as predictors for teen dating violence victimization. Violence Against Women, 22, 625-646. https://doi.org/10.1177/ 1077801215605920.

Kim, K., Mennen, F. E., \& Trickett, P. K. (2017). Patterns and correlates of co-occurrence among multiple types of child maltreatment. Child and Family Social Work, 22, 492-502. https://doi.org/10.1111/cfs. 12268.

Kinsfogel, K. M., \& Grych, J. H. (2004). Interparental conflict and adolescent dating relationships: Integrating cognitive, emotional, and peer influences. Journal of Family Psychology, 1, 505-515. https://doi.org/10.1037/0893-3200.18.3.505.

Krahé, B., \& Berger, A. (2005). Sex differences in relationship aggression among young adults in Germany. Sex Roles, 52, 829-838. https:// doi.org/10.1007/s11199-005-4202-z.

Krahé, B., \& Vanwesenbeeck, I. (2016). Mapping an agenda for the study of youth sexual aggression in Europe: Assessment, principles of good practice, and the multilevel analysis of risk factors. Journal of Sexual Aggression, 22, 161-176. https://doi.org/10.1080/ 13552600.2015.1066885.

Langer, L., \& Catani, C. (2016). Kindesmissbrauch und Reviktimisierung: Die Bedeutung unterschiedlicher Gewalttypen [Child abuse and revictimization: The significance of different types of violence]. Zeitschrift für Klinische Psychologie und Psychotherapie, 45, 279-289. https://doi.org/10.1026/1616-3443/ a000387.

Lindert, J., Von Ehrenstein, O. S., Grashow, R., Gal, G., Braehler, E., \& Weisskopf, M. G. (2014). Sexual and physical abuse in childhood is associated with depression and anxiety over the life course: Systematic review and meta-analysis. International Journal of Public Health, 59, 359-372. https://doi.org/10.1007/s00038-0130519-5.

McDonell, J., Ott, J., \& Mitchell, M. (2010). Predicting dating violence victimization and perpetration among middle and high school students in a rural southern community. Children and Youth Services Review, 32, 1458-1463. https://doi.org/10.1016/j.childyouth.2010. 07.001

Morris, A., Mrug, S., \& Windle, M. (2015). From family violence to dating violence: Testing a dual pathway model. Journal of Youth \& Adolescence, 44, 1819-1835. https://doi.org/10.1007/s10964015-0328-7.

Muthén, L. K., \& Muthén, B. O. (2017). Mplus user's guide (8th edn.). Los Angeles, CA: Muthén \& Muthén.

Neumann, D. A., Houskamp, B. M., Pollock, V. E., \& Briere, J. (1996). The long-term sequelae of childhood sexual abuse in women: A meta-analytic review. Child Maltreatment, 1, 6-16. https://doi.org/ 10.1177/1077559596001001002.
O'Keefe, M. (1997). Predictors of dating violence among high school students. Journal of Interpersonal Violence, 12, 546-568. https:// doi.org/10.1177/088626097012004005.

Ports, K. A., Ford, D. C., \& Merrick, M. T. (2016). Adverse childhood experiences and sexual victimization in adulthood. Child Abuse \& Neglect, 51, 313-322. https://doi.org/10.1016/j.physbeh.2017.03. 040 .

Price, E. L., \& Byers, E. S. (1999). The attitudes towards dating violence scales: Development and initial validation. Journal of Family Violence, 14, 351-375. https://doi.org/10.1023/A:1022830114772.

Reyes, H. L. M., Foshee, V. A., Niolon, P. H., Reidy, D. E., \& Hall, J. E. (2016). Gender role attitudes and male adolescent dating violence perpetration: Normative beliefs as moderators. Journal of Youth and Adolescence, 45, 350-360. https://doi.org/10.1007/s10964-0150278-0.

Richards, T. N., Tillyer, M. S., \& Wright, E. M. (2017). Intimate partner violence and the overlap of perpetration and victimization: Considering the influence of physical, sexual, and emotional abuse in childhood. Child Abuse and Neglect, 67, 240-248. https://doi.org/ 10.1016/j.chiabu.2017.02.037.

Roodman, A. A., \& Clum, G. A. (2001). Revictimization rates and method variance: A meta-analysis. Clinical Psychology Review, 21, 183204. https://doi.org/10.1016/S0272-7358(99)00045-8.

Schuster, I., Gul, P., Eisner, M., \& Ghuneim, L. (2020). Attitudes toward wife beating among female and male adolescents in Jordan. Journal of Interpersonal Violence. https://doi.org/10.1177/ 0886260520903131 Advance online publication.

Schuster, I., \& Krahé, B. (2019). Prevalence of sexual aggression victimization and perpetration in Chile: A systematic review. Trauma, Violence, \& Abuse, 20, 229-244. https://doi.org/10.1177/ 1524838017697307.

Schuster, I., Krahé, B., Ilabaca Baeza, P., \& Muñoz-Reyes, J. A. (2016). Sexual aggression victimization and perpetration among male and female college students in Chile. Frontiers in Psychology, 7, 1354. https://doi.org/10.3389/fpsyg.2016.01354.

Smith, P. H., White, J. W., \& Holland, L. J. (2003). A longitudinal perspective on dating violence among adolescent and college-age women. American Journal of Public Health, 93, 1104-1109. https:// doi.org/10.2105/AJPH.93.7.1104.

Smith, S. G., Chen, J., Basile, K. C., Gilbert, L. K., Merrick, M. T., Patel, N., Walling, M., \& Jain, A. (2017). The National Intimate Partner and sexual violence survey (NISVS): 2010-2012 state report. Atlanta: National Center for Injury Prevention and Control, Centers for Disease Control and Prevention. Retrieved from https://www.cdc.gov/violenceprevention/pdf/nisvs-statereportbook. pdf.

Smith-Darden, D. J. P., Kernsmith, P. D., Reidy, D. E., \& Cortina, K. S. (2017). In search of modifiable risk and protective factors for teen dating violence. Journal of Research on Adolescence, 27, 423-435. https://doi.org/10.1111/jora.12280.

Sommer, S., Reynolds, J. J., \& Kehn, A. (2016). Mock juror perceptions of rape victims. Journal of Interpersonal Violence, 31, 2847-2866. https://doi.org/10.1177/0886260515581907.

Stemple, L., Flores, A., \& Meyer, I. H. (2017). Sexual victimization perpetrated by women: Federal data reveal surprising prevalence. Aggression and Violent Behavior, 34, 302-311. https://doi.org/10. 1016/j.avb.2016.09.007.

Stoltenborgh, M., Bakermans-Kranenburg, M. J., van Ijzendoorn, M. H., \& Alink, L. R. A. (2013). Cultural-geographical differences in the occurrence of child physical abuse? A meta-analysis of global prevalence. International Journal of Psychology, 48, 81-94. https://doi. org/10.1080/00207594.2012.697165.

Stoltenborgh, M., van Ijzendoorn, M. H., Euser, E. M., \& BakermansKranenburg, M. J. (2011). A global perspective on child sexual abuse: Meta-analysis of prevalence around the world. Child 
Maltreatment, 16, 79-101. https://doi.org/10.1177/ 1077559511403920

Straus, M. A., Hamby, S. L., Boney-McCoy, S., \& Sugarman, D. B. (1996). The revised conflict tactics scales (CTS2): Development and preliminary psychometric data. Journal of Family Issues, 17, 283-316. https://doi.org/10.1177/019251396017003001.

Temple, J. R., Shorey, R. C., Tortolero, S., Wolfe, D. A., \& Stuart, G. L. (2013). Importance of attitudes about violence and gender in the relationship btween exposure to interparental violence and the perpetration of teen dating violence. Child Abuse \& Neglect, 37, 343352. https://doi.org/10.1016/j.chiabu.2013.02.001.

Tomaszewska, P., \& Krahé, B. (2016). Attitudes towards sexual coercion by Polish high school students: Links with risky sexual scripts, pornography use, and religiosity. The Journal of Sexual Aggression, 22, 291-307. https://doi.org/10.1080/13552600.2016. 1195892.

Tomaszewska, P., \& Krahé, B. (2018). Sexual aggression victimization and perpetration among female and male university students in Poland. Journal of Interpersonal Violence, 33, 571-594. https:// doi.org/10.1177/0886260515609583.

Torres, J. G., Schumm, J. A., Weatherill, R. P., Taft, C. T., Cunningham, K. C., \& Murphy, C. M. (2012). Attitudinal correlates of physical and psychological aggression perpetration and victimization in dating relationships. Partner Abuse, 3, 76-88. https://doi.org/10.1891/ 1946-6560.3.1.76.

Turner, S., Taillieu, T., Cheung, K., \& Afifi, T. O. (2017). The relationship between childhood sexual abuse and mental health outcomes among males: Results from a nationally representative United States sample. Child Abuse and Neglect, 66, 64-72. https://doi.org/10. 1016/j.chiabu.2017.01.018.

Turchik, J. A., Hebenstreit, C. L., \& Judson, S. S. (2016). An examination of the gender inclusiveness of current theories of sexual violence in adulthood: Recognizing male victims, female perpetrators, and same-sex violence. Trauma, Violence, \& Abuse, 17, 133-148. https://doi.org/10.1177/1524838014566721.

Ullman, S. E., \& Najdowski, C. J. (2011). Vulnerability and protective factors for sexual assault. In J. W. White, M. P. Koss, \& A. E. Kazdin (Eds.), Violence against women and children, Vol 1: Mapping the terrain (pp. 151-172). Washington, DC: American Psychological Association.

Vagi, K., Rothman, E., Latzman, N., Tharp, A., Hall, D., \& Breiding, M. (2013). Beyond correlates: A review of risk and protective factors for adolescent dating violence perpetration. Journal of Youth \& Adolescence, 42, 633-649. https://doi.org/10.1007/s10964-0139907-7.

Vézina, J., \& Hébert, M. (2007). Risk factors for victimization in romantic relationships of young women: A review of empirical studies and implications for prevention. Trauma, Violence, \& Abuse, 8, 33-66. https://doi.org/10.1177/1524838006297029.

WHO. (2006). Preventing child maltreatment: A guide to taking action and generating evidence. Retrieved from www.who.int/violence injury_prevention/publications/violence/child_maltreatment/en/

Wingenfeld, K., Spitzer, C., Mensebach, C., Grabe, H. J., Hill, A., Gast, U., et al. (2010). Die deutsche version des childhood trauma questionnaire (CTQ): Erste Befunde zu den psychometrischen Kennwerten [The German version of the childhood trauma questionnaire (CTQ): Preliminary psychometric properties]. PPmP Psychotherapie Psychosomatik Medizinische Psychologie, 60, 442-450. https://doi.org/10.1055/s-0030-1247564.

Witt, A., Brown, R. C., Plener, P. L., Brähler, E., \& Fegert, J. M. (2017). Child maltreatment in Germany: Prevalence rates in the general population. Child and Adolescent Psychiatry and Mental Health, 11, 1-9. https://doi.org/10.1186/s13034-017-0185-0.

Publisher's Note Springer Nature remains neutral with regard to jurisdictional claims in published maps and institutional affiliations. 